\title{
Current status and perspectives of Clonorchis sinensis and clonorchiasis: epidemiology, pathogenesis, omics, prevention and control
}

\author{
Ze-Li Tang ${ }^{1,2}$, Yan Huang ${ }^{1,2}$ and Xin-Bing Y $\mathbf{u}^{1,2^{*}}$
}

\begin{abstract}
Clonorchiasis, caused by Clonorchis sinensis (C. sinensis), is an important food-borne parasitic disease and one of the most common zoonoses. Currently, it is estimated that more than 200 million people are at risk of $C$. sinensis infection, and over 15 million are infected worldwide. C. sinensis infection is closely related to cholangiocarcinoma (CCA), fibrosis and other human hepatobiliary diseases; thus, clonorchiasis is a serious public health problem in endemic areas. This article reviews the current knowledge regarding the epidemiology, disease burden and treatment of clonorchiasis as well as summarizes the techniques for detecting C. sinensis infection in humans and intermediate hosts and vaccine development against clonorchiasis. Newer data regarding the pathogenesis of clonorchiasis and the genome, transcriptome and secretome of C. sinensis are collected, thus providing perspectives for future studies. These advances in research will aid the development of innovative strategies for the prevention and control of clonorchiasis.
\end{abstract}

Keywords: Clonorchiasis, Clonorchis sinensis, Diagnosis, Pathogenesis, Omics, Prevention

\section{Multilingual abstracts}

Please see Additional file 1 for translations of the abstract into the five official working languages of the United Nations.

\section{Review}

\section{Clonorchis sinensis (C. sinensis) and clonorchiasis}

C. sinensis is a fish-borne trematode. There are three hosts in the life cycle of $C$. sinensis including freshwater snails (the first intermediate hosts), freshwater fish and occasionally shrimps (the second intermediate hosts), and human or carnivorous mammals (the definitive hosts). The life stages of $C$. sinensis include egg (in definitive hosts or water); miracidium, sporocyst, redia, and cercaria (these four stages occur in freshwater

\footnotetext{
*Correspondence: yuhxteam@163.com

'Department of Parasitology, Zhongshan School of Medicine, Sun Yat-sen University, 74 Zhongshan 2nd Road, Guangzhou 510080, People's Republic of China

${ }^{2}$ Key Laboratory for Tropical Diseases Control, Sun Yat-sen University, Ministry of Education, Guangzhou 510080, People's Republic of China
}

snails); metacercaria (in freshwater fish); and adult (in definitive hosts) (Fig. 1) [1, 2]. Parafossarulus manchouricus ( $P$. manchouricus) is considered the main first intermediate host of $C$. sinensis in Korea, Russia, and Japan [3-6]. Melanoides tuberculata (M. tuberculata) serves as an important snail host of C. sinensis in Vietnam [7, 8]. Up to 10 species (from 3 families) of snails that are suitable for $C$. sinensis have been found in China, including Parafossarulus striatulus (P. striatulus, synonym P. manchouricus), Parafossarulus sinensis, Bithynia fuchsianus (B. fuchsianus), Parafossarulus anomalospiralis, Alocinma longicornis (A. longicornis), Bithynia misella, Semisulcospira cancellata, Semisulcospira amurensis, $M$. tuberculata, and Assiminea lutea [9]. Thus, a total of 10 species belonging to 3 families of freshwater snails can serve as first intermediate hosts [3-9], and most of these snails prefer places with a suitable climate and cool and slowmoving water (such as lakes, streams, ponds, marshes, paddy fields and small ditches). P. striatulus, A. longicornis and $B$. fuchsianus are the main freshwater snails that can be infected. Pseudorasbora parva ( $P$. parva) is the most 


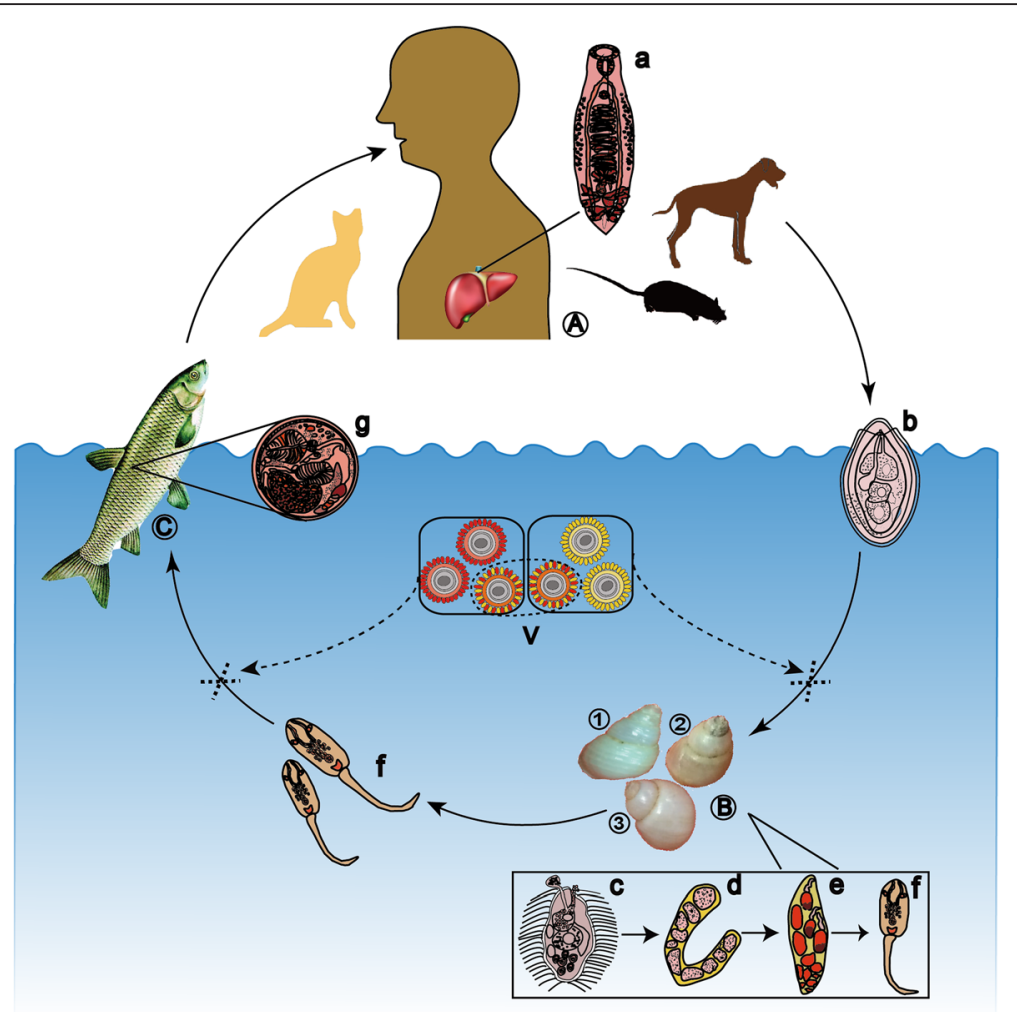

Fig. 1 The life cycle of $C$. sinensis. The adult worms of $C$. sinensis (a) mainly live in the bile ducts of the definitive hosts (A) (human beings, dogs, cats, mice, etc.). The eggs (b) are discharged from the definitive hosts with the faeces. Freshwater snails, mainly Parafossarulus striatulus (1), Bithynia fuchsianus (2) and Alocinma longicornis (3), can serve as the first intermediate hosts (B). Eggs develop into miracidia (c) in water and then to sporocysts (d), rediae (e) and cercariae (f) after they are swallowed by snails. The mature cercariae are shed from the snails, swim freely in water, and invade into the second intermediate hosts (C) (freshwater fish) through the skin and then form metacercariae $(\mathrm{g})$ in the musculature of the fish. Human or carnivorous mammals are infected due to the ingestion of raw or undercooked fish. Intervention of cercaria or metacercaria formation by effective vaccines $(V)$ will block the transmission of $C$. sinensis and fundamentally control clonorchiasis

important second intermediate host of C. sinensis, followed by other freshwater fish, such as Ctenopharyngodon idellus (C. idellus), Carassius auratus (C. auratus), Cyprinus carpio (C. carpio), Hypophthalmichthys nobilis (H. nobilis) and Saurogobio dabryi of Cyprinidae [1, 10]. In the Republic of Korea, approximately 40 species of freshwater fish (31 genera in 6 families) are suitable as second intermediate hosts of C. sinensis [11]. In China (Taiwan included), a total of 102 species of fish (59 genera in 15 families) and four species of shrimp are recognized as hosts [12]. Seven species of fish are infected by $C$. sinensis metacercariae in the Amur River of Russia [6]. In addition to humans, cats, dogs, and other carnivorous mammals can serve as natural reservoir hosts of $C$. sinensis. In addition, rats, hamsters, rabbits and mice are usually used to prepare experimental animal models of $C$. sinensis $[2,9,10]$.

The final hosts are infected with $C$. sinensis through the ingestion of raw or undercooked freshwater fish containing metacercariae. Metacercariae excyst in the duodenum of the host before moving to the bile ducts and further developing into adults [1, 13]. The adult worms can survive for a long period in the bile ducts, causing clonorchiasis in humans. Clonorchiasis generally appears as jaundice, indigestion, biliary inflammation, bile duct obstruction, even liver cirrhosis, cholangiocarcinoma (CCA), and hepatic carcinoma [13, 14]. Almost 5000 CCA cases attributed to C. sinensis infection may occur annually in the coming decades in East Asia [15]. C. sinensis is classified as a group I biocarcinogen by the International Agency for Research on Cancer (IARC) of the World Health Organization (WHO) [16].

\section{Prevalence and disease burden of clonorchiasis}

Clonorchiasis is mainly prevalent in Asian countries and regions, including South Korea, China, northern Vietnam, and far-eastern Russia [1, 14, 17]. Moreover, emigrants or travellers from endemic areas will increase the risk of disease transmission to other countries [17]. Currently, it is estimated that more than 200 million people are at risk of infection with $C$. sinensis worldwide, over 15 million people are infected, and 1.5-2 million people show symptoms or complications [13, 15, 18]. 
China has the largest population of infected people, which is estimated at 13 million $[9,17,19]$.

Two nationwide surveys (in 1989-1992 and 2001-2004) on important parasitic diseases of humans (clonorchiasis included) have been carried out in China [19-21]. Average C. sinensis infection rates found in the first and second national surveys were $0.31 \%$ and $0.58 \%$, respectively $[19,21]$. In the 2001-2004 survey, an epidemiological investigation of clonorchiasis was conducted in a total of 27 endemic provinces/autonomous regions/municipalities $(\mathrm{P} / \mathrm{A} / \mathrm{M})$. C. sinensis infection was found in a total of $19 \mathrm{P} / \mathrm{A} / \mathrm{M}$, and the average infection rate among the $27 \mathrm{P} / \mathrm{A} / \mathrm{M}$ was as high as $2.4 \%[19,20]$. It is estimated that 12.49 million individuals are infected with $C$. sinensis in mainland China; the infection rate in Guangdong province is the highest (16.4\%), followed by those in Guangxi autonomous region (9.8\%) and Heilongjiang province $(4.7 \%)[19,20]$.

The prevalence of $C$. sinensis in intermediate and reservoir hosts in China during the last decade is presented in Additional file 2: Tables S1-S3. P. striatulus, A. longicornis and $B$. fuchsianus remained the main carriers of $C$. sinensis cercariae, and the positive rates for these were $0.13-17.4 \%, 0-7.4 \%$ and $0-1.28 \%$, respectively (Additional file 2: Table S1).

Almost 31 types of freshwater fish/shrimp were reported to be infected with metacercariae of $C$. sinensis in $14 \mathrm{P} / \mathrm{A} / \mathrm{M}$ of China, most of which were members of Cyprinidae (Additional file 2: Table S2). Common edible fishes (e.g., C. idellus, C. auratus, H. nobilis, C. carpio, $H$. molitrix and M. anguillicaudatus) collected from markets, restaurants, fishponds and rivers continued to have a high probability of carrying the metacercariae of C. sinensis. Positive rates for $C$. idellus, $H$. nobilis and $C$. carpio remained high in most areas of China, especially in southern regions, such as Guangdong, Guangxi and Hunan. Moreover, the rate of infection with $C$. auratus was relatively high in Heilongjiang and Liaoning provinces. Small fish, such as P. parva, Cyprinidae Rhodeus, Abbottina rivularis and Hemicculter Leuciclus are distributed widely and are highly susceptible to infection (up to $100 \%$ ) (Additional file 2: Table S2).

The existence of reservoir hosts is closely related to the maintenance and development of the life cycle of $C$. sinensis. As shown in Additional file 2: Table S3, the prevalence of $C$. sinensis in cats and dogs was high in Guangdong, Guangxi, Heilongjiang and Jiangsu provinces, followed by Hunan, Hubei, Shandong and Liaoning. The rate of infection in cats was higher than that in dogs, and pigs were infected at lower levels. Rabbits were documented to be infected with $C$. sinensis in Heilongjiang province. Other animals, such as cattle, ducks, voles, chicken, and Rattus norvegicus were not found to be infected (Additional file 2: Table S3).
Therefore, importance should be attached to the prevention and control of reservoir host infection by feeding pets with cooked or specially processed food and improving the management of pet faeces.

In South Korea, the prevalence of egg-positive individuals was $4.6 \%$ in 1971, $1.8 \%$ in 1976, $2.6 \%$ in 1981, $2.7 \%$ in 1986, $2.2 \%$ in 1992, $1.4 \%$ in 1997 and $2.9 \%$ in 2004. It is estimated that 1.4 million people are currently infected with this fluke. People near the Nakdong River showed the highest egg-positive rate (40-48 \%) [22].

Clonorchiasis has been recorded in almost all northern provinces of Vietnam at prevalence values ranging from 0.2 to $37.5 \%$; the rates are especially high in the Red River delta region. The highest infection rate (26.0-37.5 \%) is found in Nam Dinh province, followed by Ninh Binh province (23.5-31.0\%) [23, 24]. In Russia, $C$. sinensis is mainly distributed in the southern Far East, especially near the Amur River basin, and approximately 3000 people are estimated to be infected $[15,17,25]$.

The infection rate is generally higher in males than in females. People who habitually eat raw or undercooked fish and eat outside frequently have higher infection rates than those who do not. $C$. sinensis infection is most serious in elderly people aged 40-60. Businessmen, fishermen, workers, farmers and catering staff exhibit higher infection rates [19-21].

Most cases of clonorchiasis occur in low- or middleincome countries of Asia, causing severe disease burdens and serious medical and economic problems. It is estimated that the global burden of clonorchiasis is approximately 275370 disability-adjusted life years (DALYs), and almost 5591 people die from the infection each year [18]. The calculated economic burden of clonorchiasisinduced cholecystitis, gallstones, liver cirrhosis, and liver cancer in Guangdong province (China) was RMB 1.3 billion (more than \$US 200 million) [26]. Thus far, no national investigation of the economic burden has been conducted in China or in other endemic areas. It has been documented that overall disability is higher in males than in females, and disability and infection intensity are positively correlated (gallstones are responsible for the greatest proportion) [27].

\section{Diagnosis and treatment}

Adult worms of $C$. sinensis can inhabit bile ducts for 20-25 years, and there are no obvious clinical symptoms at the early stage of the infection, often resulting in missed diagnosis [1]. In addition, clonorchiasis is usually misdiagnosed due to its nonspecific symptoms, such as fatigue, inappetence, nausea, bellyache, jaundice, and hepatosplenomegaly [15]. People who live in or have come from epidemic areas, have consumed raw or undercooked freshwater fish, and appear with the 
above symptoms should be considered suspect for clonorchiasis.

Eggs found in stool can confirm C. sinensis infection. Stool examination is inexpensive and does not require the use of sophisticated equipment; however, labour intensive, inconvenient, and well-trained staff are needed $[1,13]$. Direct faecal smear, the Kato-Katz (KK) method and the formalin-ether concentration technique (FECT) are commonly used stool examination methods for diagnosis $[28,29]$. Hong et al. reported that although FECT was more sensitive than the KK method for diagnosing very light infection cases, the KK method was more reliable for diagnosing clonorchiasis [29]. Another study demonstrated that the KK method and direct smear were suitable for the large-scale epidemiological screening of clonorchiasis [28]. Qian et al. proposed that the KK method was more reliable than FECT for the diagnosis and drug efficacy evaluation of clonorchiasis [30]. However, the eggs of $C$. sinensis are easily confused with the eggs of other flukes (e.g., Opisthorchiidae, Lecithodendriidae or Heterophyidae) $[1,13]$.

Serological methods are helpful for the diagnosis of clonorchiasis. A specific antibody or antigen of C. sinensis can theoretically be detected in serum samples. The detection of a specific antibody is more often applied than the detection of an antigen due to the trace amount of antigen present and sensitivity limitations, although Nie et al. showed that an IgY (egg yolk immunoglobulin)-based immunomagnetic bead enzyme linked immunosorbent assay (ELISA) system (IgY-IMB-ELISA) appears to be a sensitive and specific assay for the detection of circulating antigen in human clonorchiasis and a significant correlation has been found between ELISA optical density and egg counts (EPG) [31]. Crude extracts of $C$. sinensis are considered sufficiently sensitive for the serodiagnosis of clonorchiasis, but cross-react with other trematodes [13, 32]. Regarding the source and standardization of crude extracts, many purified recombinant proteins from the tegument or excretory/ secretory proteins (ESPs) of the worm such as the 21.1$\mathrm{kDa}$ tegumental protein, cathepsin $\mathrm{L}$ proteinase, cysteine protease, and a fragment of paramyosin (CsPmyC-2) [33-36] have been evaluated regarding their potential role in diagnosis. Compared with IgG-ELISA or IgG4ELISA, the IgG4-ABC (avidin-biotin complex)-ELISA that detects a specific IgG4 antibody against $C$. sinensis is more sensitive and specific [37]. Until now, two diagnostic kits (No. 3400107 and No. 3401500) that detect specific antibodies in an ELISA system have been authorized by the Chinese Food and Drug Administration (CFDA).

DNA-based methods can also be used for diagnosis. A variety of PCR techniques (including conventional PCR, real-time PCR, multiplex PCR, PCR-RFLP and FRET-
PCR) have been employed. Sensitive and specific target genes, such as internal transcribed spacers (ITS-1 or ITS-2) of nuclear ribosomal DNA (rDNA), cox1, Rn1 and nad2 have been documented [13, 38-40]. However, special equipments are required for PCR; therefore, these techniques are not suitable for use in less developed areas. Loop-mediated isothermal amplification (LAMP) is confirmed as being more sensitive, rapid and applicable in a resource-poor setting than PCR. LAMP has been successfully applied for the detection of human Opisthorchis viverrini (O. viverrini), Paragonimus westermani, Fasciola hepatica, and Fasciola gigantica, among others [41-43]; however, no effort has been made to develop LAMP or any other isothermal approaches for human clonorchiasis diagnosis.

Imaging methods including ultrasound, computer tomography $(\mathrm{CT})$, magnetic resonance imaging (MRI) and tissue harmonic imaging (THI) have important accessory diagnostic values and are also employed to assess disease progression; however, these methods exhibit relatively poor sensitivity and are nonspecific, and it can be difficult for inexperienced staff to use these methods. In addition, these techniques can be expensive to employ [1].

Clonorchiasis can be treated effectively with praziquantel (PZQ) on early accurate diagnosis and correct species identification [44]. According to WHO recommendations, treatment with doses of $25 \mathrm{mg} / \mathrm{kg}$ thrice daily for two consecutive days can achieve cure rates of 93.9-100\% $[25,45,46]$. Choi et al. conducted a clonorchiasis control project in endemic areas in China during 2001-2004 and found that repeated mass treatment or selective treatment with PZQ every 6 to 12 months was highly effective (yielding low prevalence and re-infection rates, and a high egg reduction rate) for clonorchiasis control in heavily endemic areas; in moderately endemic areas, only 1-2 selective treatments were required when combined with health education [47]. A programme involving repeated PZQ treatment at 6-month intervals was carried out in an endemic village in Korea. The egg-positive rate decreased from $22.7 \%$ (in 1994) to $6.3 \%$ (in 1998), but the treatment was insufficient to achieve the complete control of clonorchiasis [48]. Occasionally, the efficacy of PZQ against clonorchiasis is poor and fails to achieve a satisfactory effect despite long-term repeated therapy [49]. In 1997, a pilot study conducted in northern Vietnam only reached a $29 \%$ cure rate after treating clonorchiasis patients with $25 \mathrm{mg} / \mathrm{kg}$ PZQ once daily for 3 days; perhaps this dosage of PZQ is inappropriate [49]. In addition, mild and transient adverse events including dizziness, headache, vomiting, sleepiness, diarrhoea, headache, and allergy may occur after taking PZQ [17, 47, 50]. Thus, a wider choice of drugs for the treatment of clonorchiasis 
should be developed. Tribendimidine has proven highly effective for treating $C$. sinensis in vitro and in rats and hamsters [51, 52]. Two recent comparative clinical studies demonstrated that compared to PZQ, tribendimidine is as efficacious for the treatment of C. sinensis infection and in some dosage regimens is even more convenient and effective (Table 1) [53-57]. Other drugs such as artemether, artesunate, OZ78 and mebendazole have also been evaluated for treating C. sinensis infection in animal models $[58,59]$.

\section{Vaccine development}

No commercially produced or effective vaccine is available for the treatment of $C$. sinensis infection in human or other hosts as of yet. Researchers have obtained some protective effects, but only in rat models [60-68]. Quan et al. reported that rats that were pretreated with irradiated metacercariae of $C$. sinensis at the single dose of 12 Gy can generate resistance to infection, as characterized by low worm recovery, high IgG antibody titre and high levels of IFN- $\gamma$ and IL-2 [60].

The key molecules in the life cycle of $C$. sinensis (including components of ESPs, tegumental proteins, and metabolism-related enzymes) have been identified as potential vaccine candidates [69]. Worm reduction rates of $31.50,40.90,31.60$ and $37.42 \%$ were elicited by the intramuscular injection of a plasmid containing genes encoding cysteine proteinase, fatty acid-binding protein, CsPMY and enolase (CsENO), respectively [13, 61, 62]. Furthermore, worm reduction rates of $60.4,45.38,54.30$, $41.00,67.00,56.29$ and $50.20 \%$ were elicited by subcutaneous inoculation with the recombinant proteins Rho GTPase, 14-3-3 epsilon, CsPMY, cathepsin B cysteine protease 2 (CsCB2), CsCB3, CsENO and hexokinase $(\mathrm{Cs} \mathrm{HK})$, respectively [62-66]. Finally, worm reduction rates of 44.70 and $60.07 \%$ were elicited in rats by the oral delivery of Bacillus subtilis spores expressing a $22.3 \mathrm{kDa}$ tegumental protein of $C$. sinensis and CsENO, respectively [62, 67, 68].

\section{Pathogenic mechanisms of clonorchiasis}

The fact that the pathogenesis of clonorchiasis (especially liver fibrosis and CCA induced by the infection of C. sinensis) remains unclear has slowed the development of effective prevention and control strategies.

Periductal fibroplasia induced by $C$. sinensis occurs at an early stage of the infection (e.g., 7 days after infection); fibroplasia then develops into liver parenchyma (our unpublished data). The progress of this disease is different from that of the hepatic fibroplasia that results from the hepatitis induced by hepatic virus and alcohol. The molecular mechanisms that are involved in these diseases are thought to be different. ESPs from C. sinensis have been shown to play roles in the progress of this disease. As components of ESPs, secretory phospholipase A (2) (CsPLA2), lysophospholipase (CslysoPLA), fructose-1, 6-bisphosphatase (CsFBPase) and Fe heavy chain protein $(\mathrm{CsFHC})$ have been reported to directly activate human hepatic stellate cells (HSCs) and key cells in liver fibrosis and to prompt the production of collagen [70-74]. The TGF- $\beta /$ Smad signalling pathway might be activated after infection, which might contribute to the synthesis of collagen type I and fibroplasia [75]. Zheng et al. intraperitoneally injected $C$. sinensis calmodulin ( $\mathrm{Cs} \mathrm{CaM})$ into rats and observed severe liver inflammation with mild to moderate liver fibrosis as the result [76].

A study of the cancer-critical genes of $C$. sinensis-associated CCA showed that PSMD10 and CDK4 genes were upregulated, the tumour suppressor gene $p 53$ and $\mathrm{RB}$ protein as well as $B A X$ and caspase 9 were downregulated, and PCNA was overexpressed in a C. sinensisinduced hamster CCA model [77]. Several researchers have proposed that oxidative stress might mediate liver

Table 1 Therapeutic schemes and drugs for clonorchiasis

\begin{tabular}{|c|c|c|c|c|}
\hline \multicolumn{2}{|c|}{ Therapeutic regimen } & \multirow{2}{*}{$\begin{array}{l}\text { Disease information } \\
\text { Co-infection with other helminthes. }\end{array}$} & \multirow{2}{*}{$\begin{array}{l}\text { Treatment effect } \\
\text { CR: } 56.8 \% \text { (1st, 21/37), } 75 \% \\
\text { (2nd, 12/16). }\end{array}$} & \multirow{2}{*}{$\begin{array}{l}\text { References } \\
\text { [53] }\end{array}$} \\
\hline Praziquantel & Orally, 18.8 mg/kg twice daily for 2 days. & & & \\
\hline & Orally, $25 \mathrm{mg} / \mathrm{kg}$ three times for 1 day. & No other illness. & CR: $56 \%(14 / 25)$ & {$[54]$} \\
\hline & Orally, $25 \mathrm{mg} / \mathrm{kg}$ for three times. & No other illness. & CR: $62.9 \%(83 / 132)$ & {$[55]$} \\
\hline & $\begin{array}{l}\text { Orally, } 3.6 \mathrm{~g} / \mathrm{d} \text { three times daily for } 2 \text { days, } \\
\text { combined with ENBD. }\end{array}$ & Severe infection, jaundice. & Effective and safe. & {$[56]$} \\
\hline SRP & Orally, 30 mg/kg once. & Severe infection. & CR: $60 \%(12 / 20)$, side effects. & {$[57]$} \\
\hline \multirow[t]{3}{*}{ Tribendimidine } & Orally, 400 mg once. & Co-infection with other helminthes. & $\begin{array}{l}\text { CR: } 50 \%(1 s t, 17 / 34), 78.1 \% \\
\text { (2nd, 25/32). }\end{array}$ & {$[53]$} \\
\hline & Orally, 200 mg twice for 1 day. & Co-infection with other helminthes. & CR: $33.3 \%(11 / 33)$ & [53] \\
\hline & Orally, 400 mg once. & No other illness. & CR: $44 \%(11 / 25)$ & {$[54]$} \\
\hline Mebendazole & Orally, 400 mg once. & Co-infection with other helminthes. & CR: $0 \%(0 / 30)$ & {$[53]$} \\
\hline
\end{tabular}

$C R$ cure rate, ENBD endoscopic nasobiliary drainage, SRP sustained-releasing praziquantel, $1 s t$ the first treatment, $2 n d$ the second treatment 
fluke-associated carcinogenesis [78-80]. Serious pathological changes and increased DNA lesion products (resulting in the accumulation of lipid peroxidation products and the activation of COX-2 and 5-LOX) occurred in the hepatobiliary system of $C$. sinensis-infected mice, accompanied by the obvious activation of inducible NOS (iNOS) and malondialdehyde (MDA) [78-80]. The NOS-interacting protein of C. sinensis (CsNOSIP) might be a key participant in the oxidative stress observed in clonorchiasis [80].

Infection with $C$. sinensis might induce the hydropic degeneration of hepatocytes through the Fas/FasL-mediated pathway. ESPs and the components of ESPs (e.g., Csseverin) might suppress the apoptosis of malignant/ abnormal cells (HuCCT1, a CCA cell line; or PLC, a hepatocarcinoma cell line), possibly inducing the development of tumours $[13,81,82]$. Kim et al. demonstrated that ESPs of $C$. sinensis could increase the proliferation of HuCCT1 cells (a human epithelial cell line) by reducing parthenolide-induced apoptosis [82]. In another study, after treating HEK293 cells (a human epithelial cell line) with ESPs plus the carcinogen dimethylnitrosamine, the proportion of cells in the G2/M phase and the expression of cell cycle proteins (e.g., E2F1, p-pRb and cyclin B) were markedly enhanced [83]. Using microarrays, Kim et al. studied gene expression profiles in ESPtreated HuCCT1 cells, and a total of 23920 genes were found to be differently expressed. Among the upregulated genes, minichromosome maintenance protein 7 was implicated in various cancer types [84]. Evidence was obtained that ESPs can promote the threedimensional aggregation and invasion of HuCCT1 into the neighbouring extracellular matrix due to the expression of focal and cell-cell adhesion proteins and the secretion of matrix metalloproteinases [85]. Another study identified 16 dysregulated miRNAs (13 were upregulated, and 3 were down-regulated) including the decreased expression of let-7i (a tumour suppressor miRNA) when HuCCT1 cells were treated with ESPs for different times [86].

In addition, immune responses such as inflammation are proven to be involved in the pathogenesis of fibrosis and carcinoma. Nam et al. revealed that free radicals that are enzymatically triggered by $C$. sinensis ESPs can cause NF-kB-mediated inflammation in HuCCT1 cells [86]. Chronic inflammation can damage DNA and might result in the malignant transformation of cells. Crude antigens of $C$. sinensis and ESP components (e.g., CsRNASET2) might markedly elevate Th2-associated cytokines such as IL-4, IL-5 and IL-13, IL-10 and TGF- $\beta$ in $C$. sinensis-infected mice through their action on dendritic cells [87-90]. Additionally, levels of IL-33/ST2 (a potent inducer of bile duct proliferation and fibrosis) were highly increased in $C$. sinensis-infected patients and mice, and the Treg/Th17 ratio was also increased in C. sinensis-infected mice [91, 92]. Moreover, the chemokines RANTES and MIP- $1 \alpha$ were also upregulated [87]. TGF- $\beta$, IL-13 and IL-10 are well-known cytokines that can activate HSC to produce collagen types I and III (our unpublished data). These cytokines also act as antiinflammatory agents, possibly helping the worm to evade the immune response, enabling it to survive in bile ducts for a long time and finally causing long-term chronic inflammation. TLR2 and TLR4 were reported to be upregulated in a mouse model of clonorchiasis for defence against $C$. sinensis infection and pathogenicity. High TLR4 expression induced the secretion of pro-inflammatory cytokines (TNF- $\alpha$ and IFN- $\gamma$ ) in ESP-stimulated biliary epithelial cells [93, 94]. In our opinion, C. sinensis-induced liver fibrosis is a mechanism that protects the host and represents an immune pathological phenomenon, and CCA results from an imbalance between inflammation and repair.

In summary, the precise mechanisms should be further explored such that the progress of fibrosis and carcinoma can be stopped by interfering with the corresponding pathways or molecules.

\section{The genome, transcriptome and secretome of $C$. sinensis}

Omics, including genomics, transcriptomics and proteomics can help us to learn more regarding the migration, parasitism and pathogenesis of $C$. sinensis at the molecular levels, which would be extremely helpful for the development of new and effective prevention and control strategies against clonorchiasis.

The whole-genome size of $C$. sinensis was assumed to be $580 \mathrm{Mb}$, and the GC content was calculated as approximately $43.85 \%$. Heterozygosity was approximately $0.4 \%$ for the entire genome. In C. sinensis, approximately $32 \%$ of the genome constitutes interspersed repeats based on known and ab initio repeat libraries. A total of 13634 gene models were identified. Genes for the complete pathways of glycolysis, the Krebs cycle and fatty acid metabolism were found. Nearly $60 \%$ (2 203/3 $675)$ of $C$. sinensis protein domains are shared with other taxa $[69,95]$. Complementary DNA libraries were constructed from the adult, metacercaria, and egg of $C$. sinensis to obtain the gene transcript of the worm. A total of 52745 expressed sequence tags (ESTs) were generated and assembled into $12830 \mathrm{C}$. sinensis EST sequences. Energy metabolism, protease, antioxidant enzyme, motility and reproduction genes were differentially expressed in adults. Minimal metabolism and host adaptation genes were differentially expressed in metacercariae, and embryonic genes were differentially expressed in eggs [96]. Moreover, to discover new transcribed isoforms and to comprehensively characterize gene expression dynamics among different tissues, RNA-Seqs of oral 
sucker, muscle, ovary and testis tissues of $C$. sinensis were performed. Approximately $26 \%$ (3 535/13 634) of the gene models had two or more transcribed isoforms. In total, 14087 alternative-splicing events grouped into 11 different splicing patterns were detected. In addition, 4. 259 transcribed regions corresponding to 4821 transcripts were newly identified. In total, 9860 genes and 19435 transcripts were expressed in at least one tissue, and 9459 genes $(69.4 \%)$ were expressed in all four tissues from the adult worm. Differently expressing genes (DEGs) were identified: 1094 in muscle vs. oral sucker, 1315 in muscle vs. ovary, 1043 in muscle vs. testis and 516 in ovary vs. testis. Genes that were expressed at high levels in the testis were enriched in microtubule-based movement, microtubule-based processes, negative regulation of actin filament polymerization and negative regulation of protein polymerization categories. Genes that were highly expressed in both testis and ovary were enriched in spermatogenesis, sperm motility, and male gamete generation and fertilization pathways. Genes that were highly expressed in the oral sucker were enriched in pathways related to lipid binding, stimulus response and muscle differentiation, and genes that were highly expressed in muscle were enriched in pathways that are related to metabolic function [95].

The genome and transcriptome data demonstrated that the glycolysis, TCA cycle and oxidative phosphorylation pathways were similar to those for two other parasites, Schistosoma mansoni in blood and Ascaris suum in the intestine, but the pattern of fatty acid-related gene expression in C. sinensis was different [95].

Based on the genome and transcriptome data, noncoding RNA genes were identified. rRNA, tRNA, snoRNA, snRNA and miRNA were 0.0006, 0.0037, $0.0065,0.0022$ and $0.0032 \%$ of the genome, respectively [95]. Xu et al. identified and cloned 6 new and 62512 conserved adult $C$. sinensis miRNAs which are grouped into 284 families [97]. In another study, 33 novel and 18 conserved miRNAs were identified in C. sinensis (adult worms), including csi-miR-36b, which was not found by $\mathrm{Xu}$ et al. [97, 98]. The miRNAs of $C$. sinensis were concentrated along three branches of the phylogenetic tree leading to bilaterians, insects and coelomates. In total, 256990 microsatellites have been identified in the whole genome of C. sinensis through the SciRoKo programme. The ATC repeat is the most abundant microsatellite, and 24 microsatellite markers show potential application in the study of genetic diversity [99].

The ESPs of parasites play important roles in hostparasite interactions; therefore, the components and functions of ESPs have attracted the interest of researchers. Ju et al. isolated $C$. sinensis adults from experimentally infected rabbits and incubated them with PBS for $4 \mathrm{~h}$ [100]. Sixty-two protein spots were identified in the concentrated supernatant using 2-DE-based mass analysis and the EST database of $C$. sinensis. Of these, detoxification enzymes, such as glutathione S-transferase and thioredoxin peroxidase, myoglobin and a number of cysteine proteases were expressed abundantly. In another study, $C$. sinensis adults were collected from naturally infected cats and cultured in DMEM from 0 to $48 \mathrm{~h}$ at intervals of $12 \mathrm{~h}$. The supernatant containing ESP was dialysed against PBS and further analysed. In total, 110 proteins including 71 hypothetical proteins of unknown function and 39 proteins of various functional categories were identified by shotgun LC-MS/MS. The 39 proteins could be classified as glycometabolic enzymes, detoxification enzymes, structural proteins and several RAB family proteins [101]. Furthermore, ESPs from $C$. sinensis adults cultured in DMEM for different periods $(0-3 \mathrm{~h}, 3-6 \mathrm{~h}, 6-12 \mathrm{~h}, 12-24 \mathrm{~h}, 24-36 \mathrm{~h}$, and 36-48 h) were also analysed, and 187, 80, 103, 58, 248, and 383 proteins were found, respectively. Twenty-four proteins of known function and other hypothetical proteins were detected. The 24 proteins were grouped into various functional categories: ribosome proteins, enzymes, enzyme inhibitors and other proteins [102]. These studies showed that the components of ESPs might differ between definitive hosts as well as when cultured for different periods in vitro. More omics information relating to $C$. sinensis are shown in Table 2 [69, 95, 97-99, 103-106].

\section{Prevention and control strategy}

The prevention and control strategy of clonorchiasis usually involves a combination of two or more measures, including health education, health promotion, chemotherapy and environmental reconstruction [107]. The strategies proposed by the Centers for Disease Control and Prevention (CDC) of the USA, WHO, and the National Health and Family Planning Commission of the People's Republic of China (NHFPC) are summarized in Table 3 [108-110].

Health education includes the broadcast of educational programmes on television, broadcasts and VCDs, billboard/propaganda painting, the distribution of health guide booklets, and the transmission of disease-related knowledge to residents and school children [107, 111, 112]. Removing toilets and pigsties from fishpond areas is helpful in terms of environmental

Table 2 Omics information of $C$. sinensis

\begin{tabular}{ll}
\hline Genome & Draft genome $580 \mathrm{Mb}, \mathrm{GC}$ content $43.85 \%, 13634$ \\
& gene models, mitochondrial genome $13875-13879 \mathrm{bp}$, \\
& 256990 microsatellites $[69,95,99,103-105]$. \\
Transcriptome & 27082 transcripts, 88714 ORFs, 39 novel and 65530 \\
& $\begin{array}{l}\text { conserved miRNAs in adult worms, genes differentially } \\
\text { express in different stages or tissues [95, 97, 98, 106]. }\end{array}$ \\
Proteome & 50769 protein domains, participating in diverse \\
& biological processes [69, 95, 106]. \\
\hline
\end{tabular}


Table 3 Prevention and control strategies of clonorchiasis proposed by CDC, WHO and NHFPC

\begin{tabular}{|c|c|c|}
\hline CDC & $\begin{array}{l}\text { Do not eat raw or undercooked freshwater fish, cooking fish adequately } \\
\left.\text { (internal temperature }>63^{\circ} \mathrm{C}\right) \text {, freezing }\left(\leq-20^{\circ} \mathrm{C} \text { for } 7 \text { days; } \leq-35^{\circ} \mathrm{C} \text { for } 15 \mathrm{~h} \text { ). }\right.\end{array}$ & http://www.cdc.gov/parasites/clonorchis/faqs.html [108] \\
\hline WHO & $\begin{array}{l}\text { Recommending veterinary public health measures and food safety practices } \\
\text { to reduce the risk of infection, improving safe and effective of anthelminthic } \\
\text { medicines to control morbidity. }\end{array}$ & http://www.who.int/mediacentre/factsheets/fs368/en/ [109] \\
\hline NHFPC & $\begin{array}{l}\text { Improving the coverage of norms anthelmintic drugs and the sanitary toilets; } \\
\text { increasing the rates of knowledge about prevention and control of parasitic } \\
\text { and health behavior, improving the qualified rate of medical personnel in the } \\
\text { township (town) or village. }\end{array}$ & $\begin{array}{l}\text { http://www.nhfpc.gov.cn/zhuzhan/zcjd/201304/ } \\
\text { cba68ffe544c4902bd48b1cd7d41e733.shtml [110] }\end{array}$ \\
\hline
\end{tabular}

reconstruction. Health education and promotion programmes can enhance knowledge regarding $C$. sinensis infection and the need to avoid the consumption of raw or undercooked freshwater fish, which would generally promote the process of chemotherapy and environmental reconstruction.

Mass chemotherapy using PZQ has been adopted in many endemic areas and shows promise regarding the successful control of clonorchiasis [47]. Thus far, chemotherapy in combination with health education is more effective and provides a more long-lasting control than the use of chemotherapy alone [47, 107]. Considering the potential tolerance and side effects of $\mathrm{PZQ}$, the development and promotion of safe and effective anthelminthic drugs have been proposed. However, high infection rates persist in endemic areas due to the lack of culturally sensitive and educationally informed information concerning 'raw attitudes' in the eating patterns of the population [23].

Removing exposure to a raw freshwater fish/shrimp diet might be the most effective way to block infection by $C$. sinensis as well as other fish-borne zoonotic trematodes [113]. Residents in the epidemic area find it difficult to change their habit of eating raw fish/shrimp; moreover, they have more opportunities to ingest food containing raw fish. Therefore, more attention should be paid to the safety of freshwater fish. The infection rates and distribution of freshwater fish and snails should be investigated in endemic areas, and infected ponds should be placed under surveillance. Additionally, metacercaria-tainted fish should be barred from markets.

The direct compression or artificial digestion of fish followed by detection under a microscope is used to examine $C$. sinensis metacercariae in freshwater fish. This method is time consuming, labour-intensive, and $C$. sinensis is easily confused with other parasites (e.g., Opisthorchiidae, Heterophyidae and Lecithodendriidae) at this stage [113, 114]; thus, rapid, convenient and accurate detection methods are urgently needed. PCR-based molecular biology techniques including nested PCR, realtime PCR, multiplex PCR and a LAMP have been employed to detect the infection of fish and snails in recent years [113-119]. ITS-1 and ITS-2 rDNAs of $C$. sinensis are the main target genes used [113-115, 117119]. Cai et al. developed a TaqMan-based real-time PCR assay for the detection of $C$. sinensis DNA in fish; amounts as low as $1 \mathrm{pg}$ of purified genomic DNA and one metacercaria per gram of fish filet can be detected [119]. Additionally, metacercariae of $C$. sinensis and $O$. viverrini in fish can be discriminated using PCR-based techniques. Chen et al. and Cai et al. reported that the LAMP assay was $100 \sim 1000$ times more sensitive than conventional PCR for the detection of $C$. sinensis metacercariae and was more suitable for use in the field $[113,120]$. Due to their well-developed immune system, bony fish can generate specific anti-heterogeneous antigens IgM in their blood and mucus. Immunological detection is also a promising method for the rapid and accurate detection of infection in fish.

The infection rates of clonorchiasis in humans are generally and positively correlated with those in animals. High infection rates in people can usually aggravate the reservoir hosts' infection. In contrast, animals (e.g., cats and dogs) that defecate widely, accelerate the transfer of eggs into ponds and rivers, thus promoting the completion of the parasite life cycle and aggravating the epidemic [10, 121]. Infected carnivorous mammals remain large threats even if human beings have been treated. These animals are infected by the ingestion of metacercaria-containing fish. Controlling this process is an ideal way to protect fish from infection and to reduce the transmission of C. sinensis (Fig. 1). Using non-polluted water for the culture of fish combined with the use of a fish vaccine against $C$. sinensis infection will be helpful to reduce $C$. sinensis infections and aid in the supervision of the safety of freshwater fish.

\section{Research priorities for blocking transmission of the disease}

Currently, many difficulties and gaps remain in the study of blocking the transmission of this disease. First, the rate and degree of infection of the human and animal populations, and the distribution of endemic areas (e.g., in counties, towns or villages) are not clearly known or understood in real-time. The phenomena of missed diagnosis and misdiagnosis remain serious [15, 122] and delay the treatment of patients and reservoir hosts. The 
factors are the main difficulties in controlling clonorchiasis. The examination of eggs remains the gold standard for diagnosing clonorchiasis [13, 123]; however, technologies that yield rapid, convenient and accurate diagnosis are urgently required for large-scale screening and clinical application.

Second, although some researchers have obtained information regarding the developmental cycle of the parasite in snails or fish infected with $C$. sinensis under laboratory conditions [124], insufficient knowledge of the living habits, life characteristics and infection mechanism of the intermediate hosts is available. These gaps in our knowledge greatly limit us from taking effective measures to block the transmission from intermediate hosts. Practical experience tells us that biological control is superior to other means including physical or chemical control methods $[17,125]$. However, this would require a long-term major project involving parasitologists and biologists (e.g., ecologists) working in collaboration. Intervention in the growth and reproduction of freshwater snails using biological control technology and the development of effective vaccines to prevent the infection of intermediate hosts (especially freshwater fish) with $C$. sinensis are feasible control strategies.

Third, due to deficiencies and imperfections of the food safety supervision network, the decreasing degree of freshwater fish infection degree by metacercariae [113] and limitations of the detection techniques used, a large number of positive, infected freshwater fish will remain in the market. In addition to fish meat digestion, researchers are experimenting with other sensitive detection methods, such as various PCR techniques and LAMP $[116,119,120]$. However, much work remains to explore and promote suitable detection methods that can be conveniently applied to market monitoring and field investigations.

Finally, the interaction between $C$. sinensis and its hosts, and the pathogenic mechanisms involved in clonorchiasis remain unclear. We need to further clarify the molecular mechanisms and immune cytokine network involved using omics and other feasible advanced technologies $[69,95]$ to screen for molecular markers that can be used for early diagnosis and monitoring disease progression, as well as drug targets.

\section{Conclusions}

Due to the neglect and absence of systematic interventions, clonorchiasis remains prevalent worldwide, although some chemotherapy and control programmes have been implemented over several years in a few endemic areas $[23,126]$. The wide distribution of intermediate hosts and reservoir hosts, human eating habits, the lack of the food safety supervision of freshwater fish, and relatively undeveloped techniques for detection and treatment are contributing to the prevalence of clonorchiasis. New and effective prevention and control strategies are urgently required. Importantly, the rapid development in C. sinensis omics (whole-genome, transcriptome and secretome) research has provided new opportunities for revealing the physiology, parasitism and pathogenesis of C. sinensis, for identifying target molecules that can be used in the development of new antiparasitic agents, and in screening appropriate diagnostic and vaccine candidates. New methods with higher sensitivity and specificity are being developed for detecting infection in human and intermediate hosts. Promising alternative drugs (e.g., tribendimidine) have proven more effective with fewer side effects than PZQ. Moreover, the new strategies of combining non-polluted fish culture with the use of fish vaccines might represent a viable alternative to block the transmission of $C$. sinensis and ensure the food safety of freshwater fish. We are confident that sustainable and innovative control strategies may eliminate clonorchiasis in the near future.

\section{Additional files}

Additional file 1: Multilingual abstracts in the five official working languages of the United Nations. (PDF $524 \mathrm{~kb}$ )

Additional file 2: Table S1. Infection rates of $C$. sinensis in freshwater snails in China (\%). Table S2. Infection rates of C. sinensis in freshwater fish/shrimp in China (\%). Table S3. Infection rate of C. sinensis in reservoir hosts in China (\%). (DOC $201 \mathrm{~kb})$

\section{Acknowledgements}

This work was supported by grants from the National Important Sci-tech Special Projects (No. 2012ZX10004220), the Guangdong Natural Science Foundation of China (No. 2014A030313027), the Science and Technology Planning Project of Guangdong Province (No. 2013B010404010), the National Key Basic Research and Development Project of China (973 project; No. 2010CB530000).

\section{Authors' contributions}

All authors made substantial contributions to the conception and design of the study. XBY and YH designed the review. ZLT and YH contributed in writing this review. ZLT produced its figure and tables. XBY finally checked this paper. All authors read and approved the final manuscript.

\section{Competing interests}

The authors declare that they have no competing interests.

Received: 9 October 2015 Accepted: 30 June 2016

Published online: 06 July 2016

\section{References}

1. Lun ZR, Gasser RB, Lai DH, Li AX, Zhu XQ, Yu XB, et al. Clonorchiasis: a key foodborne zoonosis in China. Lancet Infect Dis. 2005;5(1):31-41.

2. Petney TN, Andrews RH, Saijuntha W, Wenz-Mücke A, Sithithaworn P. The zoonotic, fish-borne liver flukes Clonorchis sinensis, Opisthorchis felineus and Opisthorchis viverrini. Int J Parasitol. 2013;43(12-13):1031-46.

3. Yoshida Y. Clonorchiasis-a historical review of contributions of Japanese parasitologists. Parasitol Int. 2012;61(1):5-9.

4. Chung PR, Soh CT. Snail-borne parasitic zoonoses in Korea. Southeast Asian J Trop Med Public Health. 1991;22(Suppl):391-5.

5. Choi DW. Clonorchis sinensis: life cycle, intermediate hosts, transmission to man and geographical distribution in Korea. Arzneimittelforschung. 1984;34(9B):1145-51. 
6. Fattakhov RG, Ushakov AV, Stepanova TF, lanovich VA, Kopylov PV. Epizootiological characteristics of clonorchiasis foci in the Amur River ecosystem in the Jewish autonomic region. Med Parazitol (Mosk). 2012:4:15-8. (in Russian).

7. Hung NM, Dung do T, Lan Anh NT, Van PT, Thanh BN, Van Ha N, et al. Current status of fish-borne zoonotic trematode infections in Gia Vien district, Ninh Binh province, Vietnam. Parasit Vectors. 2015;8:21.

8. Kino $H$, Inaba $H$, Van De N, Van Chau L, Son DT, Hao HT, et al. Epidemiology of clonorchiasis in Ninh Binh Province, Vietnam. Southeast Asian J Trop Med Public Health. 1998;29(2):250-4

9. Ma YX, Wang H. Epidemiological evolvement of Clonorchiasis sinensis in China for the past 60 years. Int J Med Parasit Dis. 2009;36(5):362-7 (in Chinese).

10. Tang JD, Lin RQ, Zhu XQ. Animals infected with Clonorchis sinensis in China. Chin J Zoonoses. 2007;23(2):177-9 (in Chinese).

11. Sohn WM. Fish-borne zoonotic trematode metacercariae in the Republic of Korea. Korean J Parasitol. 2009;47(Suppl):S103-13.

12. Liu YS, Wu ZX. Clonorchiasis. In: Chen XB, Wu GL, Sun X, Xu SE, editors. Modern parasitology. China: People's Military Medical Publisher; 2002. p. 571-89 (in Chinese).

13. Hong ST, Fang YY. Clonorchis sinensis and clonorchiasis, an update. Parasitol Int. 2012;61(1):17-24

14. Rim HJ. Clonorchiasis: an update. J Helminthol. 2005;79(3):269-81.

15. Qian MB, Chen YD, Yan F. Time to tackle clonorchiasis in China. Infect Dis Poverty. 2013;2(1):4.

16. Bouvard V, Baan $R$, Straif $K$, Grosse $Y$, Secretan B, El Ghissassi F, et al. A review of human carcinogens-Part B: biological agents. Lancet Oncol. 2009;10(4):321-2.

17. Qian MB, Utzinger J, Keiser J, Zhou XN. Clonorchiasis. Lancet. 2016;387(10020):800-10.

18. Fürst $T$, Keiser J, Utzinger J. Global burden of human food-borne trematodiasis: a systematic review and meta-analysis. Lancet Infect Dis. 2012:12(3):210-21.

19. Coordinating Office of the National Survey on the Important Human Parasitic Diseases. A national survey on current status of the important parasitic diseases in human population. Zhongguo Ji Sheng Chong Xue Yu Ji Sheng Chong Bing Za Zhi. 2005;23 Suppl 5:332-40. in Chinese.

20. Fang YY, Chen YD, Li XM, Wu J, Zhang QM, Ruan CW. Current prevalence of Clonorchis sinensis infection in endemic areas of China. Zhongguo Ji Sheng Chong Xue Yu Ji Sheng Chong Bing Za Zhi. 2008;26(2):99-103. 109. (in Chinese).

21. Yu S, Xu L, Jiang Z, Xu S, Han J, Zhu Y, et al. Report on the first nationwide survey of the distribution of human parasites in China. 1. Regional distribution of parasite species. Zhongguo Ji Sheng Chong Xue Yu Ji Sheng Chong Bing Za Zhi. 1994;12(4):241-7 (in Chinese).

22. Shin EH, Guk SM, Kim HJ, Lee SH, Chai JY. Trends in parasitic diseases in the Republic of Korea. Trends Parasitol. 2008;24(3):143-50.

23. Sithithaworn $P$, Andrews RH, Nguyen VD, Wongsaroj T, Sinuon M, Odermatt $P$, et al. The current status of opisthorchiasis and clonorchiasis in the Mekong Basin. Parasitol Int. 2012;61(1):10-6.

24. Doanh PN, Nawa Y. Clonorchis sinensis and Opisthorchis spp. in Vietnam: current status and prospects. Trans R Soc Trop Med Hyg. 2016;110(1):13-20.

25. WHO. Control of foodborne trematode infections. Report of a WHO Study Group. WHO Tech Rep Ser. 1995;849:1-157.

26. Huang JY. Study on disease economic burden of liver and gallbladder disease caused by Clonorchis sinensis infected in Guangdong province. GuangDong Pharm Univ. 2010;5-7 (in Chinese).

27. Qian MB, Chen YD, Fang YY, Xu LQ, Zhu TJ, Tan T, et al. Disability weight of Clonorchis sinensis infection: captured from community study and model simulation. PLoS Negl Trop Dis. 2011;5(12), e1377.

28. Choi MH, Ge T, Yuan S, Hong ST. Correlation of egg counts of Clonorchis sinensis by three methods of fecal examination. Korean J Parasitol. 2005; 43(3):115-7.

29. Hong ST, Choi MH, Kim CH, Chung BS, Ji Z. The Kato-Katz method is reliable for diagnosis of Clonorchis sinensis infection. Diagn Microbiol Infect Dis. 2003:47(1):345-7.

30. Qian MB, Yap P, Yang YC, Liang H, Jiang ZH, Li W, et al. Accuracy of the Kato-Katz method and formalin-ether concentration technique for the diagnosis of Clonorchis sinensis, and implication for assessing drug efficacy. Parasit Vectors. 2013;6(1):314.

31. Nie G, Wang T, Lu S, Liu W, Li Y, Lei J. Detection of Clonorchis sinensis circulating antigen in sera from Chinese patients by immunomagnetic bead ELISA based on IgY. PLoS One. 2014;9(12), e113208.
32. Kim TI, Na BK, Hong SJ. Functional genes and proteins of Clonorchis sinensis. Korean J Parasitol. 2009;47(Suppl):S59-68.

33. Chen J, Xu H, Zhang Z, Zeng S, Gan W, Yu X, et al. Cloning and expression of 21.1-kDa tegumental protein of Clonorchis sinensis and human antibody response to it as a trematode-nematode pan-specific serodiagnosis antigen. Parasitol Res. 2011;108(1):161-8.

34. Li Y, Hu X, Liu X, Huang Y, Xu J, Zhao J, et al. Serological diagnosis of clonorchiasis: using a recombinant propeptide of cathepsin $L$ proteinase from Clonorchis sinensis as a candidate antigen. Parasitol Res. 2012;110(6):2197-203.

35. Lv X, Chen W, Wang X, Li X, Sun J, Deng C, et al. Molecular characterization and expression of a cysteine protease from Clonorchis sinensis and its application for serodiagnosis of clonorchiasis. Parasitol Res. 2012;110(6):2211-9.

36. Kang JM, Ju HL, Lee J, Kim TI, Cho SH, Kim TS, et al. Mapping of the putative epitope domain of Clonorchis sinensis paramyosin (CsPmy) recognized by CsPmy-specific immunoglobulin $\mathrm{G}$ in sera of human clonorchiasis. Mol Biochem Parasitol. 2015;201(1):66-71.

37. Wang J, Song LJ, Yu CX, Shen S, Xu YL, Yin XR, et al. Establishment and diagnostic performance of biotin-avidin complex enzyme linked immunosorbent assay of detecting specific lgG4 of clonorchiasis. Zhongguo Xue Xi Chong Bing Fang Zhi Za Zhi. 2015;27(2):156-61 (in Chinese).

38. Huang SY, Zhao GH, Fu BQ, Xu MJ, Wang CR, Wu SM, et al. Genomics and molecular genetics of Clonorchis sinensis: current status and perspectives. Parasitol Int. 2012;61(1):71-6.

39. Cho PY, Na BK, Choi KM, Kim JS, Cho SH, Lee WJ, et al. Development of a polymerase chain reaction applicable to rapid and sensitive detection of Clonorchis sinensis eggs in human stool samples. Pathog Glob Health. 2013;107(5):253-9.

40. Sanpool O, Intapan PM, Thanchomnang T, Janwan P, Lulitanond V, Doanh PN, et al. Rapid detection and differentiation of Clonorchis sinensis and Opisthorchis viverrini eggs in human fecal samples using a duplex real-time fluorescence resonance energy transfer PCR and melting curve analysis. Parasitol Res. 2012;111(1):89-96.

41. Arimatsu Y, Kaewkes S, Laha T, Hong SJ, Sripa B. Rapid detection of Opisthorchis viverrini copro-DNA using loop-mediated isothermal amplification (LAMP). Parasitol Int. 2012;61(1):178-82.

42. Chen MX, Ai L, Zhang RL, Xia JJ, Wang K, Chen SH, et al. Sensitive and rapid detection of Paragonimus westermani infection in humans and animals by loopmediated isothermal amplification (LAMP). Parasitol Res. 2011;108(5):1193-8.

43. Ai L, Li C, Elsheikha HM, Hong SJ, Chen JX, Chen SH, et al. Rapid identification and differentiation of Fasciola hepatica and Fasciola gigantica by a loop-mediated isothermal amplification (LAMP) assay. Vet Parasitol. 2010;174(3-4):228-33.

44. Choi BI, Han JK, Hong ST, Lee KH. Clonorchiasis and cholangiocarcinoma: etiologic relationship and imaging diagnosis. Clin Microbiol Rev. 2004:17(3):540-52

45. Xu FN. Comparative study on different dosage-schedules of praziquantel in treating 376 cases of clonorchiasis. Anhui Med J. 1986:1:33-5 (in Chinese).

46. Lee SH. Large scale treatment of Clonorchis sinensis infections with praziquantel under field conditions. Arzneimittelforschung. 1984;34(9B):1227-30.

47. Choi MH, Park SK, Li Z, Ji Z, Yu G, Feng Z, et al. Effect of control strategies on prevalence, incidence and re-infection of clonorchiasis in endemic areas of China. PLoS Negl Trop Dis. 2010;4(2), e601.

48. Hong ST, Yoon K, Lee M, Seo M, Choi MH, Sim JS, et al. Control of clonorchiasis by repeated praziquantel treatment and low diagnostic efficacy of sonography. Korean J Parasitol. 1998;36(4):249-54.

49. Tinga N, De N, Vien HV, Chau L, Toan ND, Kager PA, et al. Little effect of praziquantel or artemisinin on clonorchiasis in Northern Vietnam. A pilot study. Trop Med Int Health. 1999;4(12):814-8.

50. Lee JM, Lim HS, Hong ST. Hypersensitive reaction to praziquantel in a clonorchiasis patient. Korean J Parasitol. 2011;49(3):273-5.

51. Xiao SH, Xue J, Xu LL, Zheng Q, Qiang HQ, Zhang YN, et al. The in vitro and in vivo effect of tribendimidine and its metabolites against Clonorchis sinensis. Parasitol Res. 2009;105(6):1497-507.

52. Xue J, Xu LL, Qiang HQ, Zhang YN, Xiao SH. Therapeutic effect of tribendimidine, artesunate and praziquantel administered to hamsters infected with Clonorchis sinensis. Chin J Parasitol Parasit Dis. 2009;27(3):215-8.

53. Xu LL, Jiang B, Duan JH, Zhuang SF, Liu YC, Zhu SQ, et al. Efficacy and safety of praziquantel, tribendimidine and mebendazole in patients with co-infection of Clonorchis sinensis and other helminths. PLoS Negl Trop Dis. 2014;8(8), e3046. 
54. Qian MB, Yap P, Yang YC, Liang H, Jiang ZH, Li W, et al. Efficacy and safety of tribendimidine against Clonorchis sinensis. Clin Infect Dis. 2013;56(7):e76-82.

55. Choi D, Jeon YH, Lee GC, Choi MH, Hong ST. Changes in sonographic findings after treatment of patients with clonorchiasis in a heavy endemic area. Korean J Parasitol. 2009;47(1):19-23.

56. Zhi FC, Liu XM, Liu ZQ, Lin Y, Chen SJ. Treatment of severe Clonorchiasis sinensis by endoscopic nasobiliary drainage and orally praziquantel. World J Gastroenterol. 2004;10(14):2150-2.

57. Choi MH, Chang BC, Lee SJ, Jang IJ, Shin SG, Kho WG, et al. Therapeutic evaluation of sustained-releasing praziquantel (SRP) for clonorchiasis: phase 1 and 2 clinical studies. Korean J Parasitol. 2006;44(4):361-6.

58. Kim TI, Yoo WG, Li S, Hong ST, Keiser J, Hong SJ. Efficacy of artesunate and artemether against Clonorchis sinensis in rabbits. Parasitol Res. 2009;106(1):153-6.

59. Keiser J, Vargas M. Effect of artemether, artesunate, OZ78, praziquantel, and tribendimidine alone or in combination chemotherapy on the tegument of Clonorchis sinensis. Parasitol Int. 2010;59(3):472-6.

60. Quan FS, Lee JB, Bae JS, Ohwatari N, Min YK, Yang HM. Resistance to reinfection in rats induced by irradiated metacercariae of Clonorchis sinensis. Mem Inst Oswaldo Cruz. 2005;100(5):549-54.

61. Wang $X$, Chen W, Lv X, Tian Y, Men J, Zhang X, et al. Identification and characterization of paramyosin from cyst wall of metacercariae implicated protective efficacy against Clonorchis sinensis infection. PLoS One. 2012;7(3), e33703.

62. Wang X, Chen W, Tian Y, Mao Q, Lv X, Shang M, et al. Surface display of Clonorchis sinensis enolase on Bacillus subtilis spores potentializes an oral vaccine candidate. Vaccine. 2014:32(12):1338-45.

63. Xie HY, Hu XC, Xu J, Yu XB. Protective immunity of Cs-Rho GTPase recombinant protein against Clonorchis sinensis infection. Zhongguo Ji Sheng Chong Xue Yu Ji Sheng Chong Bing Za Zhi. 2010;28(3):176-9 (in Chinese).

64. Wang X, Chen W, Li X, Zhou C, Deng C, Lv X, et al. Identification and molecular characterization of a novel signaling molecule 14-3-3 epsilon in Clonorchis sinensis excretory/secretory products. Parasitol Res. 2012;110(4):1411-20.

65. Chen W, Wang X, Lv X, Tian Y, Xu Y, Mao Q, et al. Characterization of the secreted cathepsin $B$ cysteine proteases family of the carcinogenic liver fluke Clonorchis sinensis. Parasitol Res. 2014;113(9):3409-18.

66. Chen T, Yu J, Tang Z, Xie Z, Lin Z, Sun H, et al. Advanced enzymology, expression profile and immune response of Clonorchis sinensis hexokinase show its application potential for prevention and control of clonorchiasis. PLoS Negl Trop Dis. 2015;9(3), e0003641.

67. Zhou Z, Xia H, Hu X, Huang Y, Li Y, Li L, et al. Oral administration of a Bacillus subtilis spore-based vaccine expressing Clonorchis sinensis tegumental protein $22.3 \mathrm{kDa}$ confers protection against Clonorchis sinensis. Vaccine. 2008:26(15):1817-25.

68. Yu J, Chen T, Xie Z, Liang P, Qu H, Shang M, et al. Oral delivery of Bacillus subtilis spore expressing enolase of Clonorchis sinensis in rat model: induce systemic and local mucosal immune responses and has no side effect on liver function. Parasitol Res. 2015;114(7):2499-505.

69. Wang X, Chen W, Huang Y, Sun J, Men J, Liu H, et al. The draft genome of the carcinogenic human liver fluke Clonorchis sinensis. Genome Biol. 2011;12(10):R107.

70. Wang $X$, Hu F, Hu X, Chen W, Huang Y, Yu X. Proteomic identification of potential Clonorchis sinensis excretory/secretory products capable of binding and activating human hepatic stellate cells. Parasitol Res. 2014;113(8):3063-71.

71. Hu F, Hu X, Ma C, Zhao J, Xu J, Yu X. Molecular characterization of a novel Clonorchis sinensis secretory phospholipase $A(2)$ and investigation of its potential contribution to hepatic fibrosis. Mol Biochem Parasitol. 2009:167(2):127-34.

72. Zhang F, Liang P, Chen W, Wang X, Hu Y, Liang C, et al. Stage-specific expression, immunolocalization of Clonorchis sinensis lysophospholipase and its potential role in hepatic fibrosis. Parasitol Res. 2013;112(2):737-49.

73. Liang P, Sun J, Huang Y, Zhang F, Zhou J, Hu Y, et al. Biochemical characterization and functional analysis of fructose-1, 6-bisphosphatase from Clonorchis sinensis. Mol Biol Rep. 2013;40(7):4371-82.

74. Mao Q, Xie Z, Wang X, Chen W, Ren M, Shang M, et al. Clonorchis sinensis ferritin heavy chain triggers free radicals and mediates inflammation signaling in human hepatic stellate cells. Parasitol Res. 2015;114(2):659-70.

75. Yan C, Wang L, Li B, Zhang BB, Zhang B, Wang YH, et al. The expression dynamics of transforming growth factor- $B / S$ mad signaling in the liver fibrosis experimentally caused by Clonorchis sinensis. Parasit Vectors. 2015;8:70.
76. Zheng M, Hu K, Liu W, Yu X. Characterization of a Clonorchis sinensis antigen, calmodulin, and its relationship with liver fibrosis. Nan Fang Yi Ke Da Xue Xue Bao. 2015;35(5):659-64 (in Chinese),

77. Uddin MH, Choi MH, Kim WH, Jang JJ, Hong ST. Involvement of PSMD10, CDK4, and Tumor Suppressors in Development of Intrahepatic Cholangiocarcinoma of Syrian Golden Hamsters Induced by Clonorchis sinensis and N-Nitrosodimethylamine. PLoS Negl Trop Dis. 2015;9(8), e0004008.

78. Yang QL, Shen JQ, Xue Y, Cheng XB, Jiang ZH, Yang YC, et al. Pathological lesions and inducible nitric oxide synthase expressions in the liver of mice experimentally infected with Clonorchis sinensis. Korean J Parasitol. 2015:53(6):777-83.

79. Maeng S, Lee HW, Bashir Q, Kim TI, Hong SJ, Lee TJ, et al. Oxidative stressmediated mouse liver lesions caused by Clonorchis sinensis infection. Int J Parasitol. 2016;46(3):195-204.

80. Bian $\mathrm{M}, \mathrm{Xu} \mathrm{Q}, \mathrm{Xu}$ Y, Li S, Wang X, Sheng J, et al. Investigation on oxidative stress of nitric oxide synthase interacting protein from Clonorchis sinensis. Parasitol Res. 2016;115(1):77-83.

81. Chen X, Li S, He L, Wang X, Liang P, Chen W, et al. Molecular characterization of severin from Clonorchis sinensis excretory/secretory products and its potential anti-apoptotic role in hepatocarcinoma PLC cells. PLoS Negl Trop Dis. 2013;7(12), e2606.

82. Kim YJ, Choi MH, Hong ST, Bae YM. Resistance of cholangiocarcinoma cells to parthenolide-induced apoptosis by the excretory-secretory products of Clonorchis sinensis. Parasitol Res. 2009;104(5):1011-6.

83. Kim EM, Kim JS, Choi MH, Hong ST, Bae YM. Effects of excretory/secretory products from Clonorchis sinensis and the carcinogen dimethylnitrosamine on the proliferation and cell cycle modulation of human epithelial HEK293T cells. Korean J Parasitol. 2008:46(3):127-32.

84. Kim DW, Kim JY, Moon JH, Kim KB, Kim TS, Hong SJ, et al. Transcriptional induction of minichromosome maintenance protein 7 (Mcm7) in human cholangiocarcinoma cells treated with Clonorchis sinensis excretory-secretory products. Mol Biochem Parasitol. 2010;173(1):10-6.

85. Won J, Ju JW, Kim SM, Shin Y, Chung S, Pak JH. Clonorchis sinensis infestation promotes three-dimensional aggregation and invasion of cholangiocarcinoma cells. PLoS One. 2014;9(10), e110705.

86. Nam JH, Moon JH, Kim IK, Lee MR, Hong SJ, Ahn JH, et al. Free radicals enzymatically triggered by Clonorchis sinensis excretory-secretory products cause NF-kB-mediated inflammation in human cholangiocarcinoma cells. Int J Parasitol. 2012;42(1):103-13.

87. Kim EM, Bae YM, Choi MH, Hong ST. Cyst formation, increased antiinflammatory cytokines and expression of chemokines support for Clonorchis sinensis infection in FVB mice. Parasitol Int. 2012;61(1):124-9.

88. Jin Y, Wi HJ, Choi MH, Hong ST, Bae YM. Regulation of anti-inflammatory cytokines IL-10 and TGF- $\beta$ in mouse dendritic cells through treatment with Clonorchis sinensis crude antigen. Exp Mol Med. 2014;46, e74.

89. Xu Y, Chen W, Bian M, Wang X, Sun J, Sun H, et al. Molecular characterization and immune modulation properties of Clonorchis sinensis-derived RNASET2. Parasit Vectors. 2013;6:360.

90. Xu Y, Lin J, Bian M, Chen W, Liang P, Wang X, et al. CsRNASET2 is an important component of Clonorchis sinensis responsible for eliciting Th2 immune response. Parasitol Res. 2015;114(6):2371-9.

91. Yu Q, Li XY, Cheng XD, Shen LP, Fang F, Zhang B, et al. Expression and potential roles of IL-33/ST2 in the immune regulation during Clonorchis sinensis infection. Parasitol Res. 2016;5 [Epub ahead of print].

92. Yan C, Zhang BB, Hua H, Li B, Zhang B, Yu Q, et al. The Dynamics of Treg/ Th17 and the Imbalance of Treg/Th17 in Clonorchis sinensis-Infected Mice. PLoS One. 2015;10(11), e0143217.

93. Yan C, Li XY, Li B, Zhang BB, Xu JT, Hua H, et al. Expression of Toll-like receptor (TLR) 2 and TLR4 in the livers of mice infected by Clonorchis sinensis. J Infect Dev Ctries. 2015:9(10):1147-55.

94. Yan C, Wang YH, Yu Q, Cheng XD, Zhang BB, Li B, et al. Clonorchis sinensis excretory/secretory products promote the secretion of TNF-alpha in the mouse intrahepatic biliary epithelial cells via Toll-like receptor 4. Parasit Vectors. 2015;8:559.

95. Huang $Y$, Chen W, Wang $X$, Liu H, Chen Y, Guo L, et al. The carcinogenic liver fluke, Clonorchis sinensis: new assembly, reannotation and analysis of the genome and characterization of tissue transcriptomes. PLoS One. 2013:8(1), e54732

96. Yoo WG, Kim DW, Ju JW, Cho PY, Kim TI, Cho SH, et al. Developmental transcriptomic features of the carcinogenic liver fluke, Clonorchis sinensis. PLoS Negl Trop Dis. 2011;5(6), e1208. 
97. Xu MJ, Liu Q, Nisbet AJ, Cai XQ, Yan C, Lin RQ, et al. Identification and characterization of microRNAs in Clonorchis sinensis of human health significance. BMC Genomics. 2010;11:521.

98. Ovchinnikov VY, Afonnikov DA, Vasiliev GV, Kashina EV, Sripa B, Mordvinov VA, et al. Identification of microRNA genes in three opisthorchiids. PLoS Negl Trop Dis. 2015;9(4), e0003680.

99. Nguyen TT, Arimatsu Y, Hong SJ, Brindley PJ, Blair D, Laha T, et al. Genomewide characterization of microsatellites and marker development in the carcinogenic liver fluke Clonorchis sinensis. Parasitol Res. 2015;114(6):2263-72.

100. Ju JW, Joo HN, Lee MR, Cho SH, Cheun HI, Kim JY, et al. Identification of a serodiagnostic antigen, legumain, by immunoproteomic analysis of excretory-secretory products of Clonorchis sinensis adult worms. Proteomics. 2009;9(11):3066-78.

101. Zheng M, Hu K, Liu W, Hu X, Hu F, Huang L, et al. Proteomic analysis of excretory secretory products from Clonorchis sinensis adult worms: molecular characterization and serological reactivity of a excretory-secretory antigen-fructose-1,6-bisphosphatase. Parasitol Res. 2011;109(3):737-44.

102. Zheng M, Hu K, Liu W, Li H, Chen J, Yu X. Proteomic analysis of different period excretory secretory products from Clonorchis sinensis adult worms: molecular characterization, immunolocalization, and serological reactivity of two excretory secretory antigens-methionine aminopeptidase 2 and acid phosphatase. Parasitol Res. 2013;112(3):1287-97.

103. Cai XQ, Liu GH, Song HQ, Wu CY, Zou FC, Yan HK, et al. Sequences and gene organization of the mitochondrial genomes of the liver flukes Opisthorchis viverrini and Clonorchis sinensis (Trematoda). Parasitol Res. 2012;110(1):235-43.

104. Shekhovtsov SV, Katokhin AV, Kolchanov NA, Mordvinov VA. The complete mitochondrial genomes of the liver flukes Opisthorchis felineus and Clonorchis sinensis (Trematoda). Parasitol Int. 2010;59(1):100-3.

105. Liu GH, Li B, Li JY, Song HQ, Lin RQ, Cai XQ, et al. Genetic variation among Clonorchis sinensis isolates from different geographic regions in China revealed by sequence analyses of four mitochondrial genes. J Helminthol. 2012;86(4):479-84.

106. Young ND, Campbell BE, Hall RS, Jex AR, Cantacessi C, Laha T, et al. Unlocking the transcriptomes of two carcinogenic parasites, Clonorchis sinensis and Opisthorchis viverrini. PLoS Negl Trop Dis. 2010;4(6), e719.

107. Wu W, Qian X, Huang Y, Hong Q. A review of the control of clonorchiasis sinensis and Taenia solium taeniasis/cysticercosis in China. Parasitol Res. 2012;111(5):1879-84.

108. Centers for Disease Control and Prevention. Parasites - Clonorchis. 2014. http://www.cdc.gov/parasites/clonorchis/faqs.html. Accessed 15 Mar 2016.

109. World Health Organization. Foodborne trematodiases. 2015. http://www. who.int/mediacentre/factsheets/fs368/en/. Accessed 15 Mar 2016.

110. National Health and Family Planning Commission of the People's Republic of China. The prevention and control plan of national key parasitic diseases in 2006-2015 year. 2006. http://www.nhfpc.gov.cn/zhuzhan/zcjd/201304/ cba68ffe544c4902bd48b1cd7d41e733.shtml. Accessed 15 Mar 2016.

111. Qian MB. Clonorchiasis control: starting from awareness. Infect Dis Poverty. 2014;3:33.

112. Huang $X, L i Z$, Fang $Y$, Ruan $C$, Zhang $X$, Liu D, et al. Effect of comprehensive control in demonstration plot of clonorchiasis in Yangshan County, 2006-2009. Zhongguo Xue Xi Chong Bing Fang Zhi Za Zhi. 2011;23(5):569-70. 574. (in Chinese).

113. Chen Y, Wen T, Lai DH, Wen YZ, Wu ZD, Yang TB, et al. Development and evaluation of loop-mediated isothermal amplification (LAMP) for rapid detection of Clonorchis sinensis from its first intermediate hosts, freshwater snails. Parasitology. 2013;140(11):1377-83.

114. Traub RJ, Macaranas J, Mungthin M, Leelayoova S, Cribb T, Murrell KD, et al. A new PCR-based approach indicates the range of Clonorchis sinensis now extends to Central Thailand. PLoS Negl Trop Dis. 2009;3(1), e367.

115. Müller B, Schmidt J, Mehlhorn H. Sensitive and species-specific detection of Clonorchis sinensis by PCR in infected snails and fishes. Parasitol Res. 2007;100(4):911-4.

116. Parvathi A, Sanath Kumar H, Kenchanna Prakasha B, Lu J, Xu X, Hu W, et al. Clonorchis sinensis: development and evaluation of a nested polymerase chain reaction (PCR) assay. Exp Parasitol. 2007;115(3):291-5.

117. Huang SY, Tang JD, Song HQ, Fu BQ, Xu MJ, Hu XC, et al. A specific PCR assay for the diagnosis of Clonorchis sinensis infection in humans, cats and fishes. Parasitol Int. 2012;61(1):187-90.

118. Zhang Y, Chang QC, Zhang Y, Na L, Wang WT, Xu WW, et al. Prevalence of Clonorchis sinensis infection in freshwater fishes in northeastern China. Vet Parasitol. 2014;204(3-4):209-13.
119. Cai XQ, Yu HQ, Bai JS, Tang JD, Hu XC, Chen DH, et al. Development of a TaqMan based real-time PCR assay for detection of Clonorchis sinensis DNA in human stool samples and fishes. Parasitol Int. 2012;61(1):183-6.

120. Cai XQ, Xu MJ, Wang YH, et al. Sensitive and rapid detection of Clonorchis sinensis infection in fish by loop-mediated isothermal amplification (LAMP). Parasitol Res. 2010;106(6):1379-83.

121. Ngo KZ, Ermolenko AV. The spread of the pathogen of human and animal clonorchiasis in North Vietnam. Med Parazitol (Mosk). 2011;4:39-41. (in Russian).

122. Xu J, Xu JF, Li SZ, Zhang LJ, Wang Q, Zhu HH, et al. Integrated control programmes for schistosomiasis and other helminth infections in P.R. China. Acta Trop. 2015;141(Pt B):332-41.

123. Lai DH, Hong XK, Su BX, Liang C, Hide G, Zhang $X$, et al. Current status of Clonorchis sinensis and clonorchiasis in China. Trans R Soc Trop Med Hyg. 2016;110(1):21-7.

124. Liang $C$, Hu XC, Lv ZY, Wu ZD, Yu XB, Xu J, et al. Experimental establishment of life cycle of Clonorchis sinensis. Zhongguo Ji Sheng Chong Xue Yu Ji Sheng Chong Bing Za Zhi. 2009;27(2):148-50 (in Chinese).

125. Hung NM, Duc NV, Stauffer Jr JR, Madsen H. Use of black carp (Mylopharyngodon piceus) in biological control of intermediate host snails of fish-borne zoonotic trematodes in nursery ponds in the Red River Delta, Vietnam. Parasit Vectors. 2013;6:142.

126. Chen DY, Wang JJ, Zang W, Qian MB, Xu QL. Cost-effectiveness analysis of integrated control strategy of parasitic diseases in demonstration plots. Zhongquo Xue Xi Chong Bing Fang Zhi Za Zhi. 2011;23(5):501-5 (in Chinese).

\section{Submit your next manuscript to BioMed Central and we will help you at every step:}

- We accept pre-submission inquiries

- Our selector tool helps you to find the most relevant journal

- We provide round the clock customer support

- Convenient online submission

- Thorough peer review

- Inclusion in PubMed and all major indexing services

- Maximum visibility for your research

Submit your manuscript at www.biomedcentral.com/submit
(O) BioMed Central 